\title{
Identification and Characterization of Immunodominant Proteins from Tick Tissue Extracts Inducing a Protective Immune Response against Ixodes ricinus in Cattle
}

\author{
Sarah Knorr ${ }^{1,+}$, Sophia Reissert-Oppermann ${ }^{1,+}{ }^{+}$, Julen Tomás-Cortázar $^{2}{ }^{\mathbb{D}}$, Diego Barriales ${ }^{3} \mathbb{C}^{\mathbb{C}}$,

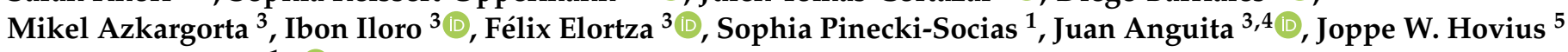 \\ and Ard M. Nijhof 1 ,*DiD \\ check for \\ updates \\ Citation: Knorr, S.; Reissert- \\ Oppermann, S.; Tomás-Cortázar, J.; \\ 1 Institute for Parasitology and Tropical Veterinary Medicine, Freie Universität Berlin, 14163 Berlin, Germany; \\ knorr.sarah.j@gmail.com (S.K.); sophia.reissert@googlemail.com (S.R.-O.); \\ Sophia.Pinecki@fu-berlin.de (S.P.-S.) \\ 2 School of Biomolecular and Biomedical Science, University College Dublin, Belfield, D04 V1W8 Dublin 4, \\ Ireland; julen.tomascortazar@ucd.ie \\ 3 CIC bioGUNE-BRTA (Basque Research and Technology Alliance), 48162 Derio, Spain; \\ dbarriales@cicbiogune.es (D.B.); mazkargorta@cicbiogune.es (M.A.); iiloro@cicbiogune.es (I.I.); \\ felortza@cicbiogune.es (F.E.); janguita@cicbiogune.es (J.A.) \\ 4 Ikerbasque, Basque Foundation for Science, 48009 Bilbao, Spain \\ 5 Center for Experimental and Molecular Medicine, Academic Medical Center, University of Amsterdam, \\ 1105 AZ Amsterdam, The Netherlands; lyme@amc.uva.nl \\ * Correspondence: ard.nijhof@fu-berlin.de; Tel.: +49-(0)30-838-62326 \\ + Both authors contributed equally to this work.
} Barriales, D.; Azkargorta, M.; Iloro, I.; Elortza, F.; Pinecki-Socias, S.; Anguita, J.; Hovius, J.W.; et al. Identification and Characterization of Immunodominant Proteins from Tick Tissue Extracts Inducing a Protective Immune Response against Ixodes ricinus in Cattle. Vaccines 2021, 9, 636. https://doi.org/10.3390/

vaccines 9060636

Academic Editor: Ralph A. Tripp

Received: 26 April 2021

Accepted: 8 June 2021

Published: 10 June 2021

Publisher's Note: MDPI stays neutral with regard to jurisdictional claims in published maps and institutional affiliations.

Copyright: (c) 2021 by the authors. Licensee MDPI, Basel, Switzerland. This article is an open access article distributed under the terms and conditions of the Creative Commons Attribution (CC BY) license (https:// creativecommons.org/licenses/by/ $4.0 /)$.
Abstract: Ixodes ricinus is the main vector of tick-borne diseases in Europe. An immunization trial of calves with soluble extracts of I. ricinus salivary glands (SGE) or midgut (ME) previously showed a strong response against subsequent tick challenge, resulting in diminished tick feeding success. Immune sera from these trials were used for the co-immunoprecipitation of tick tissue extracts, followed by LC-MS/MS analyses. This resulted in the identification of 46 immunodominant proteins that were differentially recognized by the serum of immunized calves. Some of these proteins had previously also drawn attention as potential anti-tick vaccine candidates using other approaches. Selected proteins were studied in more detail by measuring their relative expression in tick tissues and RNA interference (RNAi) studies. The strongest RNAi phenotypes were observed for MG6 (A0A147BXB7), a protein containing eight fibronectin type III domains predominantly expressed in tick midgut and ovaries of feeding females, and SG2 (A0A0K8RKT7), a glutathione-Stransferase that was found to be upregulated in all investigated tissues upon feeding. The results demonstrated that co-immunoprecipitation of tick proteins with host immune sera followed by protein identification using LC-MS/MS is a valid approach to identify antigen-antibody interactions, and could be integrated into anti-tick vaccine discovery pipelines.

Keywords: Ixodes ricinus; immunoprecipitation; anti-tick vaccines; midgut; salivary glands

\section{Introduction}

Ixodes ricinus is a three-host ixodid tick species that is widely distributed in Western Europe. It is the predominant vector of several pathogens of medical and veterinary relevance, including tick-borne encephalitis virus (TBEV), Borrelia burgdorferi sensu lato (the causal agent of Lyme borreliosis), and Babesia divergens [1]. Besides their capacity to transmit a wide variety of pathogens, it was recently demonstrated that the saliva of $I$. ricinus contained galactose- $\alpha-1,3$-galactose ( $\alpha$-Gal)-carrying proteins, which are associated with the induction of an anti- $\alpha-$ Gal immune response in humans and may result in red meat allergy $[2,3]$. The prevention and control of diseases associated with $I$. ricinus relies 
on a combination of methods including the avoidance of tick habitats, the prompt removal of ticks, the use of repellents and acaricides, and landscaping measures [4].

Vaccines targeting ticks and the blocking of pathogen transmission are attractive alternative control options, and their development is drawing increasing interest [4-7]. Anti-tick vaccines targeting the common cattle tick Rhipicephalus microplus have been successfully developed and commercialized in the last century [8,9]. These vaccines are based on a single recombinant antigen, Bm86, a protein located in the microvilli of the tick midgut. This protein was identified following a laborious and long process involving multiple immunization trials, in which the effect of immunization with increasingly simpler fractions of tick midgut extracts on tick infestation was evaluated [10]. The artificial feeding of blood and plasma of animals immunized with tick midgut extracts showed that antibodies, in the presence of complement, were able to damage tick gut cells, thereby reproducing some of the detrimental effects observed in $R$. microplus ticks fed directly on immunized cows [11]. Antisera raised against recombinant Bm86 also partially inhibited larval engorgement of one-host $R$. australis (formerly $R$. microplus) ticks [12]. Our group recently immunized calves with different organ tissue homogenates of $I$. ricinus and found that the immunization with the soluble extracts of all tick organs, salivary glands, or midgut alone also conferred significant protection against subsequent challenge with I. ricinus nymphs and adults [13]. The identification of antibody-antigen complexes responsible for disrupting tick feeding could therefore be of relevance in the identification of tickprotective antigens.

In this study, we co-immunoprecipitated tick tissue extracts with pre- and post-immune sera from the I. ricinus immunization trial followed by label-free liquid chromatography-mass spectrometry (LC-MS/MS) to identify proteins that were differentially recognized by the serum of calves immunized with salivary gland extracts (SGE) or midgut extracts (ME). The results were partially validated by Western blotting, and the gene expression profile of selected antigens in tick organs was measured by quantitative reverse transcription PCR (RT-PCR). Finally, we analyzed the loss-of function phenotype for 10 of the identified proteins by RNA interference (RNAi).

\section{Materials and Methods}

\subsection{Ticks and Animals}

All $I$. ricinus ticks used originated from a laboratory colony maintained at the tick breeding unit of the Institute for Parasitology and Tropical Veterinary Medicine of the Freie Universität Berlin.

\subsection{Protein Extracts and Antisera}

Salivary glands and midguts were dissected from washed ticks and kept in sterile PBS on ice. The tissues were subsequently homogenized using an ultrasonic homogenizer (Hielscher, UP100H) and centrifuged at $15,000 \times g$ for $30 \mathrm{~min}$ at $4{ }^{\circ} \mathrm{C}$. The supernatant was filtered through $0.4 \mu \mathrm{m}$ and $0.2 \mu \mathrm{m}$ non-pyrogenic filters (Sarstedt, Nümbrecht, Germany) and stored at $-20^{\circ} \mathrm{C}$. The bovine antisera used originated from calves immunized with tick protein extracts, as recently described [13]. Antisera were collected at day 0 (pre-immune sera) and day 68 (post-immune sera).

\subsection{Direct Antigen Co-Immunoprecipitation}

Control and immune calf sera IgG were purified using the Melon Gel IgG Spin Purification Kit (Thermo Scientific, Rockford, IL, USA), following the manufacturer's protocol. Protein content was then measured in midgut and salivary gland lysates using the Pierce BCA Protein Assay Kit (Thermo Scientific, Rockford, IL, USA). Direct immunoprecipitation was performed using the Pierce Direct IP Kit (Thermo Scientific, Rockford, IL, USA) following the manufacturer's instructions. Enrichment was carried out by incubation of $100 \mu \mathrm{L}$ of the AminoLink Plus Coupling Resin slurry with $20 \mu \mathrm{L}$ purified serum that was immobilized onto the aldehyde-activated agarose resin at room temperature for $2 \mathrm{~h}$. One 
milligram of the tissue lysates was added to each antibody-coupled resin in a spin column. The column was incubated with gentle shaking at $4{ }^{\circ} \mathrm{C}$ overnight to form antibody-antigen complexes. After several washes, the antigens were eluted in $100 \mu \mathrm{L}$.

\subsection{Tryptic Digestion}

SDS-PAGE bands of the immunoprecipitated antigens were cut and washed in milli$\mathrm{Q}$ water. Reduction and alkylation were performed using ditiothreitol (10 $\mathrm{mM}$ DTT in $50 \mathrm{mM}$ ammonium bicarbonate) at $56{ }^{\circ} \mathrm{C}$ for $20 \mathrm{~min}$, followed by iodoacetamide ( $50 \mathrm{mM}$ iodoacetamide in $50 \mathrm{mM}$ ammonium bicarbonate) at room temperature for another $20 \mathrm{~min}$ in the dark. Gel pieces were dried and incubated with trypsin $(12.5 \mu \mathrm{g} / \mathrm{mL}$ in $50 \mathrm{mM}$ ammonium bicarbonate) for $20 \mathrm{~min}$ on ice. After rehydration, the trypsin supernatant was discarded; gel pieces were hydrated with $50 \mathrm{mM}$ ammonium bicarbonate, and incubated overnight at $37^{\circ} \mathrm{C}$. After digestion, tryptic peptides were recovered and dried in an RVC2 25 speedvac concentrator (Christ, Osterode, Germany). The peptides were resuspended in $10 \mu \mathrm{L} 0.1 \%$ formic acid and sonicated for $5 \mathrm{~min}$ prior to analysis.

\subsection{LC-MS/MS Analysis}

LC was performed using an NanoAcquity nano-HPLC (Waters, Milford, MA, USA) apparatus equipped with a Waters BEH C18 nano-column (200 $\mathrm{mm} \times 75 \mathrm{um}$ ID, $1.8 \mu \mathrm{m})$. A chromatographic ramp of $120 \mathrm{~min}$ ( 5 to $60 \% \mathrm{ACN}$ ) was used with a flow rate of $300 \mathrm{~nL} / \mathrm{min}$. Mobile phase A was water containing $0.1 \% v / v$ formic acid, while mobile phase $\mathrm{B}$ was ACN containing $0.1 \% v / v$ formic acid. A lock mass compound, [Glu1]-Fibrinopeptide B $(100 \mathrm{fmol} / \mu \mathrm{L})$, was delivered by an auxiliary pump of the $\mathrm{LC}$ system at $500 \mathrm{~nL} / \mathrm{min}$ to the reference sprayer of the NanoLockSpray (Waters) source of the mass spectrometer. For each run, $0.5 \mu \mathrm{g}$ of each sample was loaded.

For mass spectrometry, we used a Synapt G2Si ESI Q-Mobility-TOF spectrometer (Waters) equipped with an ion mobility chamber (T-Wave-IMS) for high-definition data acquisition analyses. All analyses were performed in positive-mode ESI. Data were postacquisition lock mass-corrected using the double-charged monoisotopic ion of [Glu1]Fibrinopeptide B. Accurate mass LC-MS/MS data analysis was performed in HDDA mode, which is an enhanced form of data-dependent acquisition that enhances signal intensities using the ion mobility separation step.

Database searching was performed using MASCOT 2.2.07 (Matrixscience, London, UK) against a custom UNIPROT-Swissprot/Trembl database filled only with entries corresponding to Ixodes and B. burgdorferi. For protein identification, the following parameters were adopted: carbamidomethylation of cysteines (C) as a fixed modification and oxidation of methionines $(\mathrm{M})$ as variable modifications, $15 \mathrm{ppm}$ of peptide mass tolerance, $0.2 \mathrm{Da}$ fragment mass tolerance, up to 3 missed cleavage points, and peptide charges of +2 and +3 . Only peptides with a false discovery rate $<1 \%$ were selected.

\subsection{Cloning and Purification}

The MG9 (A0A131YAQ2) and SG4 (A0A0K8RQF1) genes were cloned by overlapping PCR from midgut or salivary gland cDNA and cloned as EcoRI-XhoI or NcoI-SalI fragments, respectively, into the pHIS-parallel 2 expression vector. Sequence-confirmed clones were induced with $1 \mathrm{mM}$ isopropyl- $\beta$-D-thiogalactoside (IPTG) for $16 \mathrm{~h}$ at $20^{\circ} \mathrm{C}$ in E. coli BL21 C41(DE3). The bacterial cells were then lysed and centrifuged. The expressed proteins were extracted from the inclusion bodies using the following protocol: the pellet was thoroughly homogenized in $50 \mathrm{mM}$ Tris ( $\mathrm{pH}$ 8), $300 \mathrm{mM} \mathrm{NaCl}, 1 \mathrm{mM} \mathrm{DTT}$, and $2 \%$ Triton $\mathrm{X}-100$, followed by an incubation at $37^{\circ} \mathrm{C}$ for $30 \mathrm{~min}$. The sample was ultracentrifuged at $96,000 \times g$ for $30 \mathrm{~min}$ and the pellet was homogenized again in $50 \mathrm{mM}$ Tris (pH 8), $300 \mathrm{mM}$ $\mathrm{NaCl}$, and $1 \mathrm{mM} \mathrm{DTT}$, and incubated at $37^{\circ} \mathrm{C}$ for $30 \mathrm{~min}$. After a second ultracentrifugation, the pellet was homogenized in $50 \mathrm{mM}$ Tris $\mathrm{pH} 8,300 \mathrm{mM} \mathrm{NaCl}, 1 \mathrm{mM}$ DTT, and $7 \mathrm{M}$ urea. The denatured proteins were refolded by dialysis in PBS overnight with an intermediate exchange of buffer to a final concentration of $2 \mathrm{M}$ urea. 


\subsection{Western Blotting}

For the validation or recognition of tick antigens by bovine immune sera, $5 \mu \mathrm{g}$ of each extract or purified protein were boiled at $95^{\circ} \mathrm{C}$ for $10 \mathrm{~min}$, subjected to SDS-PAGE, and transferred to a nitrocellulose membrane at $200 \mathrm{~V}$ for $1 \mathrm{~h}$. The membranes were blocked with 5\% non-fat milk in Tris-buffered saline solution containing $0.01 \%$ Tween-20 (TBS-T). The membranes were immunoblotted with diluted pre-immunization control sera (d0) and post-immunization sera (d68) (1:500) at $4{ }^{\circ} \mathrm{C}$ overnight.

\subsection{Bioinformatics Analysis}

The BLASTp tool was used to infer the potential function by homology. Signal peptides were predicted by SignalP (http:/ / www.cbs.dtu.dk/services/SignalP/, accessed on 15 August 2019). Transmembrane helices were predicted using the TMHMM server (http:/ / www.cbs.dtu.dk/services/TMHMM/, accessed on 15 August 2019).

\subsection{RNA Isolation}

Tissues were dissected from unfed I. ricinus females and females pre-fed for 3-5 days on rabbits. Three biological replicates were made for each tissue type. Prior to dissection, ticks were washed for $30 \mathrm{~s}$ in $70 \%$ ethanol. Dissections were performed on a glass slide under ice-cold phosphate-buffered saline (PBS, pH 7.2). Internal organs were stored in TRI Reagent (Sigma-Aldrich, Taufkirchen, Germany) on ice and homogenized by passage through 24- and 27-gauge needles. Total RNA was subsequently isolated by chloroform phase separation and isopropanol precipitation, followed by DNase treatment (Thermo Fisher Scientific, Darmstadt, Germany). Sample concentrations and purity were measured using a Synergy HT Spectrophotometer (Bio-Tek Instruments, Bad Friedrichshall, Germany).

\subsection{Quantitative RT-PCR}

cDNA was synthesized from 100 ng of DNA-free RNA from the salivary glands, midguts, Malpighian tubules, ovaries, and fat bodies of unfed and partially fed I. ricinus females using the iScript cDNA synthesis kit (Bio-Rad laboratories, Feldkirchen, Germany) according to the manufacturer's instructions and stored at $-20^{\circ} \mathrm{C}$. Quantitative RT-PCRs were performed for 15 targets identified in the LC-MS/MS analysis as being differentially recognized by immune sera and for the genes targeted by RNAi (see below). Two references genes, elongation factor 1-alpha (ELF1A) [14] and ATP synthase subunit g (ATP5L), were used for normalization purposes. ATP5L was used as a reference gene as it was recently found to be an abundant and stably expressed gene in Borrelia afzelii-infected as well as uninfected I. ricinus ticks in a quantitative transcriptomics study [15]. A list of primers used for quantitative RT-PCRs is presented in Table 1. All PCRs were conducted in a Bio-Rad CFX qPCR cycler. RT-PCR amplification mixtures $(25 \mu \mathrm{L})$ contained $12.5 \mu \mathrm{L}$ of Advanced Universal SYBR Green Supermix (Bio-Rad Laboratories), $2.5 \mu \mathrm{L}$ cDNA template, $400 \mathrm{nM}$ of both forward and reverse primer, and $8 \mu \mathrm{L}$ water. The cycling conditions were $30 \mathrm{~s}$ at $95^{\circ} \mathrm{C}$ followed by 40 cycles of $95^{\circ} \mathrm{C}$ for $10 \mathrm{~s}$ and $60^{\circ} \mathrm{C}$ for $30 \mathrm{~s}$. A melt curve analysis was performed from 65 to $95^{\circ} \mathrm{C}$ with a $0.5{ }^{\circ} \mathrm{C}$ increment with $2 \mathrm{~s} / \mathrm{step}$. All assays included a no-template control for each gene. Gene expression was analyzed using CFX Maestro software (Bio-Rad). 
Table 1. Details of the quantitative RT-PCRs performed in this study.

\begin{tabular}{|c|c|c|c|c|}
\hline Target & UNIPROT ID & Forward Primer $\left(5^{\prime}-3^{\prime}\right)$ & Reverse Primer $\left(5^{\prime}-3^{\prime}\right)$ & $\begin{array}{l}\text { Amplicon } \\
\text { Length (bp) }\end{array}$ \\
\hline ELF1A & & CAAGATTGGTGGTATCGGCA & GACCTCAGTGGTGATGTTGGC & 106 \\
\hline ATP5L & & CGAAAGCCATCACTACCCTG & TCTCCACCTTGGCATACTTGAC & 85 \\
\hline MG1 & A0A131XWI1 & GGATGTGGTTTTACCCCGTC & CCCTCTTGAGCGTTGGATG & 115 \\
\hline MG2 & V5IFB6 & CTCTGGAAACCTGGACAACG & GCAGCGTGAAAGATAGAGTCC & 131 \\
\hline MG3 & V5HWP4 & AATCGCCAGTTGTCAGAAGC & TCAAGCCGACAGCAAATATG & 76 \\
\hline MG4 & V5I2L3 & CACTGGTCATCTCCTGGCTC & CGTGCTCTTGTACATAAGGTCTG & 137 \\
\hline MG5 & A0A0K8R8I3 & GTCTCTGCTTCGGTGTCTCC & GGCGACTTGAGGTTGTAGG & 83 \\
\hline MG6 & A0A147BXB7 & GAGACTCCCAAGGACAAGAACC & TGTAGAGATATTTTTGCCACCAGG & 78 \\
\hline MG7 & V5IJN2 & CCGAAGTCTCCAAGGGTCC & ACCGACTCCATCGTCAAAAAG & 116 \\
\hline MG8 & A0A147BMG4 & GACAACACCACGGCACAGG & GGTGTAGGGCTTGAAGTTGTAGAA & 92 \\
\hline MG9 & A0A131YAQ2 & GGGGATTTCCGAAGCCAC & CTGAAGATATTGTTGACGGGGTC & 146 \\
\hline MG10 & V5H492 & AAACGGGCATCAGCAAAGC & TTGTTGAGATCGCCAGCAGAC & 97 \\
\hline MG11 & A0A131XS30 & CATTCGTAGATCACACCCTGC & CGGCGATTCGTAGCGTG & 107 \\
\hline SG1 & V5HWD5 & CCACTACGAAGGCTACCACAA & CCTATTCAGCCCTGTCCATC & 56 \\
\hline SG2 & A0A0K8RKT7 & TTGCCTACGAGATGCTGTCC & TGAACTTGTCCGACTTGAGGT & 135 \\
\hline SG3 & A0A0K8RPW5 & AGTTTACGAGCTTCTCTTGCC & TCCGTCGTGAACACTACCG & 102 \\
\hline SG4 & A0A0K8RQF1 & CTTCCGAAGAGTGTCAGGGTGA & GTGCCGAATGCCGACTGC & 108 \\
\hline
\end{tabular}

\subsection{RNA Interference}

For the RNAi experiment, cDNA was synthesized from RNA isolated from tick tissues using the Superscript III first-strand cDNA synthesis kit (Thermo Fisher Scientific, Darmstadt, Germany) according to the manufacturer's instructions. Oligonucleotide primers (Sigma-Aldrich, Taufkirchen, Germany) containing a T7 promotor sequences at the $5^{\prime}$-end were used to amplify partial fragments of the genes coding for 10 target genes and green fluorescent protein (GFP) (Table 2). PCR products were purified using the DNA Clean and Concentrator kit (Zymo Research, Freiburg im Breisgau, Germany) following the manufacturer's recommendations and used as templates to produce dsRNA using the T7 Ribomax Express RNAi system (Promega, Walldorf, Germany) according to the manufacturer's instructions.

In the RNAi experiment, the effect of silencing the expression of 10 genes identified by the LC-MS/MS analysis was evaluated. Ticks were divided into 10 groups of 40 female ticks each that were subsequently injected with $0.5 \mu \mathrm{L}$ of dsRNA $\left(1 \times 10^{12}\right.$ molecules $/ \mu \mathrm{L}$ dissolved in $10 \mathrm{mM}$ Trish- $\mathrm{HCl}, \mathrm{pH} 7$ and $1 \mathrm{mM}$ EDTA) coding for one of the selected targets. Female $I$. ricinus ticks were injected in the lower right quadrant using a $10 \mu \mathrm{L}$ syringe with a 33-gauge needle (Hamilton) mounted on a micromanipulator. As a negative control, 80 ticks were equally divided over two groups and injected with dsRNA coding for GFP. Following injection with dsRNA, ticks were incubated at RT and 90\% relative humidity for $24 \mathrm{~h}$. The ticks were thereafter fed on six rabbits, with one group per ear. The two negative control groups injected with GFP dsRNA fed on different rabbits. For the confirmation of gene silencing by quantitative RT-PCR, the RNA from the salivary glands or midguts of six female ticks fed for five days from each group were collected and analyzed in three biological triplicates of two ticks each. Engorged females were weighed individually, and oviposition data were not recorded. 
Table 2. List of primers used for dsRNA synthesis. All primers contained a T7 promoter sequence $\left(5^{\prime}-\right.$ TAATACGACTCACTATAGG-3') on their $5^{\prime}$ end. GFP: green fluorescent protein.

\begin{tabular}{cccc}
\hline Target & Forward Primer $\left(\mathbf{5}^{\prime} \mathbf{-} \mathbf{3}^{\prime} \mathbf{)}\right.$ & Reverse Primer $\mathbf{( 5}^{\prime} \mathbf{- 3}^{\prime} \mathbf{)}$ & Amplicon Length (bp) \\
\hline MG1 & T7-CCCTTCCATCTTGCGGTAGC & T7-CGAACGAAGAGCGGAACG & 393 \\
MG2 & T7-GAATCCCCAGTCCAAGATGATC & T7-CTTTCGTGACCGCTCGTTC & 538 \\
MG4 & T7-CAGACATCGGCAAGGGTG & T7-GAGCCAGGAGATGACCAGTG & 229 \\
MG6 & T7-GCGGACGAAGAGGAATACG & T7-GCTAAGAGTAACATTGGTGTATCC & 493 \\
MG7 & T7-ACCACATCTGCCAACGGAG & T7-ATCCCAAGTAGGAAGCCGTT & 257 \\
MG8 & T7-ACTTTGCTTTCTTGGCATCGG & T7-GTCGTATGTGTTGCCTTTGTCG & 429 \\
MG9 & T7-GGTGGCATTGACAACGCTCTC & T7-GAACTTCTTCGTCGCTTCCTTG & 400 \\
MG10 & T7-GGCTCCAGAAAACACAATCCTC & T7-CCTTTTCCGTGGTAGAATGGG & 666 \\
MG11 & T7-CCAGGATGGGAAAGTGCGAC & T7-GAACGCCAGCGAACCAGG & 243 \\
SG2 & T7-CCAAACCTGCCCTACTACCTG & T7-GGACAGCATCTCGTAGGCAAT & 324 \\
GFP & T7-GGCCACAAGTTCAGCGTGTC & T7-GCTTGATGCCGTTCTTCTGC & 415 \\
\hline
\end{tabular}

\subsection{Statistical Analysis}

Statistical analysis of data from the weights of ticks after feeding was performed using GraphPad Prism version 5.03 for Windows. The proportion of ticks that successfully engorged were analyzed by chi-squared test. Tick weights were compared between the experimental and combined GFP-injected groups using a $t$-test with Welch's correction. Quantitative RT-PCR data was analyzed using the Bio-Rad CFX Maestro software. $p$-values of 0.05 or less were considered statistically significant.

\section{Results}

3.1. Identification of Differentially Recognized Proteins from ME and SGE by Immune Sera of Calves Immunized with ME and SGE

In order to identify immunodominant proteins from SGE and ME, we immunoblotted midgut and salivary gland extracts using pre-immunization control sera $(\mathrm{d} 0)$ and post immunization sera (d68) from calves. Both sera showed specific recognition of proteins in SGE and ME extracts that were not recognized by control sera (Figure 1).

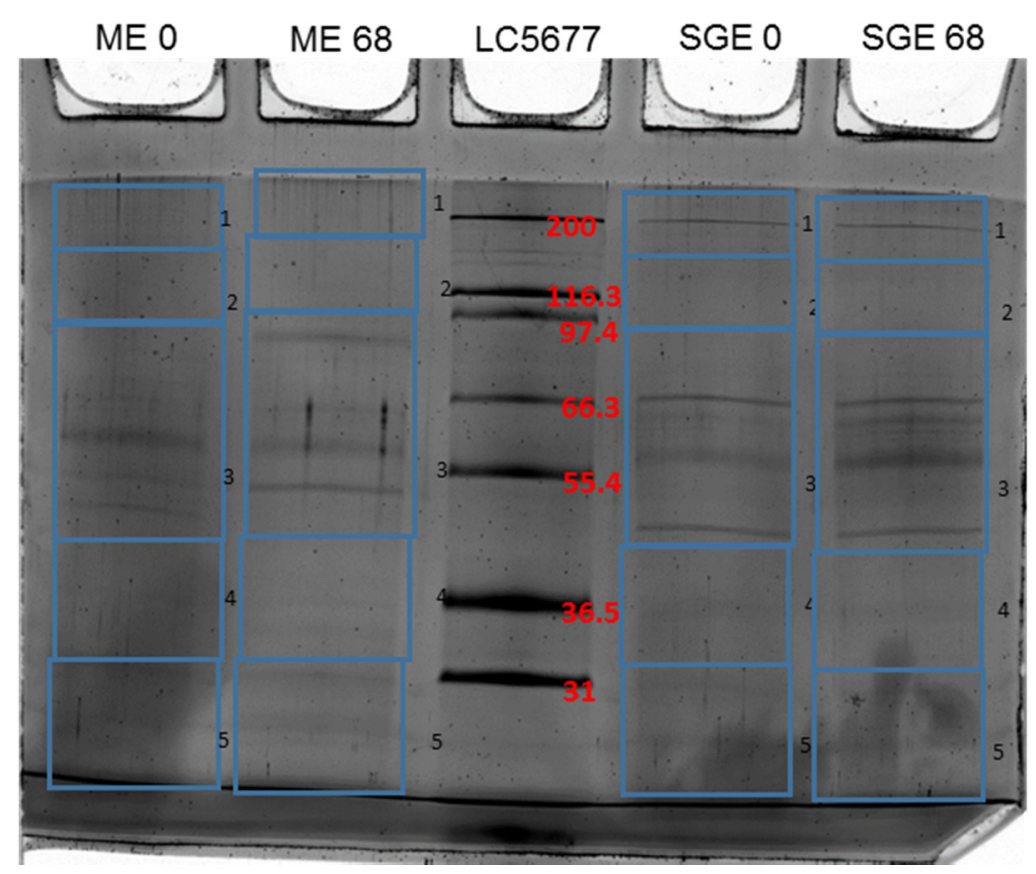

Figure 1. The SDS-PAGE gel of the immunoprecipitation complexes was cut as depicted, followed by in-gel tryptic digestion for the proteomic analysis. Abbreviations-ME: midgut extract; SGE: salivary gland extracts; LC5677: Mark12 protein marker (Invitrogen). 
SGE antisera identified 167 unique peptides which could be linked to 55 proteins in the Uniprot database. Alignment of these proteins with their closest BLASTp hits revealed that four of the Uniprot entries (V5I085/A0A131Y1S2 and V5HWD5/A0A0K8RPW5) actually represented different fragments of two proteins, reducing the total number of uniquely identified proteins to 53 . Of these proteins, five were only recognized by control sera and 24 exclusively by immune sera. A total of 24 proteins were identified in SGE-immunoprecipitates with both $\mathrm{d} 0$ and $\mathrm{d} 68$ sera (Table 3). In the ME, 78 unique peptides were found that could be linked to 46 proteins. Again, four UNIPROT entries (V5H0K4/A0A147BSS4 and A0A131Y7G4/A0A090X8W5) actually represented different fragments of two proteins, reducing the number of unique proteins to 44 proteins. A total of eight proteins were identified in ME-immunoprecipitates with both $\mathrm{d} 0$ and $\mathrm{d} 68$ sera, while 14 were identified by the control sera, and 22 by the immune sera (Table 4). Finally, 13 proteins were present in both SGE and ME immunoprecipitates, 10 of which in both d0 and d68 sera. A single protein, heat shock protein 60 (A0A131XPM3), was recognized by d68 sera of both SGE and ME immunized calves.

Table 3. List of proteins identified by LC-MS/MS from Ixodes ricinus salivary gland extracts (SGE) following coimmunoprecipitation with antisera raised against SGE. The Mascot score reflects the combined scores of all observed mass spectra that matched to amino acid sequences within the respective protein. MW: molecular weight.

\begin{tabular}{|c|c|c|c|c|c|c|c|}
\hline $\begin{array}{c}\text { Uniprot } \\
\text { Accession Code }\end{array}$ & Protein Name & $\begin{array}{l}\text { \# of Unique } \\
\text { Peptides }\end{array}$ & $\begin{array}{c}\text { Mascot } \\
\text { Score d0 }\end{array}$ & $\begin{array}{c}\text { Mascot } \\
\text { Score d68 }\end{array}$ & $\begin{array}{c}\text { MW } \\
(\mathrm{kDa})\end{array}$ & pI & $\begin{array}{l}\text { Signal } \\
\text { Peptide }\end{array}$ \\
\hline V5H4T2 & $\begin{array}{l}\text { Trifunctional purine biosynthetic protein } \\
\text { adenosine-3 }\end{array}$ & 1 & 41.20 & 71.91 & 7.3 & 8.19 & No \\
\hline V5HMC9 & Small nuclear ribonucleoprotein $\mathrm{G}$, putative & 1 & & 54.37 & 8.4 & 8.54 & No \\
\hline V5IF42 & Myosin-2 essential light chain & 1 & 40.41 & & 9.7 & 6.51 & No \\
\hline V5HG94 & $60 \mathrm{~S}$ ribosomal protein $\mathrm{L} 22$ & 2 & 76.25 & 88.50 & 9.9 & 10.01 & No \\
\hline A0A0K8RQM9 & Small nuclear ribonucleoprotein Sm D3 & 1 & & 58.85 & 13.2 & 10.13 & No \\
\hline V5IJC3 & 60s ribosomal protein L11 & 1 & 128.84 & 79.57 & 13.2 & 10.62 & No \\
\hline A0A0K8RIJ1 & Histone $\mathrm{H} 2 \mathrm{~A}$ & 1 & & 50.33 & 13.4 & 10.73 & No \\
\hline A0A131Y512 & $40 S$ ribosomal protein S16 & 1 & & 32.98 & 14.9 & 10.04 & No \\
\hline V5HG43 & Stromal cell-derived factor 2 , putative & 1 & 34.15 & & 15.2 & 10.32 & No \\
\hline A0A090XEK9 & Myosin, essential light chain & 2 & 41.67 & 44.63 & 15.5 & 4.94 & No \\
\hline V5HWD5 & Metalloproteinase (=SG1) a & 1 & & 44.26 & 16.9 & 9.92 & No \\
\hline A0A0K8RC23 & $40 \mathrm{~S}$ ribosomal protein $\mathrm{S} 13$ & 1 & & 33.57 & 17.2 & 10.68 & No \\
\hline A0A0K8RL33 & Superoxide-dismutase & 1 & & 35.85 & 18.1 & 6.64 & Yes \\
\hline V5HD78 & 60S ribosomal protein L6 & 4 & 62.85 & 57.09 & 18.6 & 10.33 & No \\
\hline V5I150 & 60S ribosomal protein L5-A & 3 & 94.73 & 50.00 & 19.0 & 7.84 & No \\
\hline V5I135 & Alpha-crystallin A chain * & 1 & 54.14 & & 20.3 & 7.64 & No \\
\hline V5HXA8 & $60 \mathrm{~S}$ ribosomal protein L18 & 2 & 60.03 & 131.89 & 21.5 & 11.62 & No \\
\hline V5H3S3 & $60 S$ ribosomal L23 & 2 & & 67.50 & 21.6 & 11.39 & No \\
\hline A0A0K8RQ35 & $40 \mathrm{~S}$ ribosomal protein $\mathrm{S} 8$ & 1 & & 40.95 & 21.9 & 10.30 & No \\
\hline A0A0K8RKT7 & Glutathione S-transferase (=SG2) & 1 & & 39.95 & 25.5 & 7.88 & No \\
\hline A0A0K8RPW5 & Metalloproteinase (=SG3) ${ }^{\text {a }}$ & 1 & & 45.77 & 26.6 & 9.45 & Yes \\
\hline V5I164 & Tropomyosin, isoform close to $\mathrm{X} 4$ & 3 & 145.00 & 57.96 & 26.6 & 5.34 & No \\
\hline A0A0K8RHG9 & Tubulin alpha chain & 1 & & 62.27 & 27.1 & 5.57 & No \\
\hline A0A0K8RQF1 & Toll-like receptor, putative (=SG4) & 1 & & 41.27 & 27.6 & 8.31 & Yes \\
\hline A0A131XW65 & $60 S$ ribosomal protein L7 & 1 & 79.15 & 70.36 & 29.2 & 10.98 & No \\
\hline A0A0K8RG40 & $40 \mathrm{~S}$ ribosomal protein $\mathrm{S} 4$ & 3 & 74.40 & 81.92 & 29.6 & 10.29 & No \\
\hline A0A0K8RG01 & $\begin{array}{l}\text { Glyceraldehyde-3-phosphate dehydrogenase } \\
2 \text {, isoform X1 * }\end{array}$ & 1 & & 51.70 & 36.0 & 7.84 & No \\
\hline V5HG89 & ATP synthase subunit beta & 2 & & 87.40 & 36.3 & 5.03 & No \\
\hline
\end{tabular}


Table 3. Cont.

\begin{tabular}{|c|c|c|c|c|c|c|c|}
\hline E3SS18 & Translation elongation factor EF1-alpha * & 4 & 63.01 & 184.99 & 36.7 & 8.27 & No \\
\hline A0A147BVX5 & $\begin{array}{c}\text { Venom metalloproteinase antarease-like } \\
\text { TtrivMP_A }\end{array}$ & 1 & 34.45 & & 38.8 & 5.83 & Yes \\
\hline Q5D579 & Actin * & 9 & 401.51 & 335.42 & 41.5 & 5.85 & No \\
\hline A0A0K8RDN7 & $\begin{array}{l}\text { Protein N-myc downstream-regulated gene } 3 \\
\text { (NDRG3) isoform X1 }\end{array}$ & 2 & 46.54 & 88.18 & 44.6 & 6.54 & No \\
\hline A0A0K8RCY6 & Tubulin beta chain & 3 & 40.59 & 127.53 & 45.1 & 5.97 & No \\
\hline A0A131XРA0 & $\begin{array}{c}\text { Eukaryotic translation initiation factor } 3 \\
\text { subunit } \mathrm{M}\end{array}$ & 1 & & 36.48 & 45.2 & 5.97 & No \\
\hline A0A0K8RMJ6 & $60 S$ ribosomal protein L4 & 1 & & 37.81 & 46.6 & 11.19 & No \\
\hline V5I085 & $\begin{array}{c}\text { Microsomal triglyceride transfer protein large } \\
\text { subunit }{ }^{b}\end{array}$ & 1 & 36.01 & 58.33 & 48.0 & 6.89 & No \\
\hline A0A0K8R4C2 & $\begin{array}{l}\text { Dolichyl-diphosphooligosaccharide-protein } \\
\text { glycosyltransferase } 48 \mathrm{kDa} \text { subunit }\end{array}$ & 1 & & 37.19 & 48.8 & 6.05 & Yes \\
\hline A0A0K8R4D7 & Cytochrome b-c1 complex subunit 2 & 3 & 105.77 & 115.65 & 48.9 & 8.62 & No \\
\hline A0A131Y1S2 & $\begin{array}{c}\text { Microsomal triglyceride transfer protein large } \\
\text { subunit }{ }^{b}\end{array}$ & 2 & 36.65 & 51.53 & 49.7 & 8.97 & Yes \\
\hline V5I095 & $\begin{array}{l}\text { S-adenosylhomocysteine hydrolase-like } \\
\text { protein }\end{array}$ & 4 & & 93.01 & 50.5 & 6.54 & No \\
\hline A0A131XNF3 & Processing peptidase beta subunit, putative * & 2 & 105.08 & 87.93 & 53.4 & 6.15 & No \\
\hline A0A0K8RCY2 & Metis1 & 4 & 149.35 & 176.93 & 55.5 & 7.58 & Yes \\
\hline A0A131XPM3 & Heat shock protein $60 *$ & 5 & & 151.93 & 59.3 & 5.62 & No \\
\hline A0A0K8RCE8 & Heat shock $70 \mathrm{kDa}$ protein cognate $4 *$ & 2 & 60.97 & 115.44 & 59.8 & 7.43 & No \\
\hline A0A0K8RP16 & $\begin{array}{l}\text { Dolichyl-diphosphooligosaccharide-protein } \\
\text { glycosyltransferase subunit } 1\end{array}$ & 3 & & 115.81 & 67.5 & 7.53 & Yes \\
\hline A0A090XC63 & Moesin/ezrin/radixin homolog 1 isoform X1 * & 7 & 81.17 & 206.20 & 70.1 & 5.66 & No \\
\hline A0A0K8RIU3 & Heat shock protein, putative * & 3 & 66.94 & 102.00 & 72.6 & 5.41 & Yes \\
\hline V5HP83 & Coatomer subunit alpha & 2 & & 61.57 & 75.6 & 8.79 & No \\
\hline A0A0K8R8N9 & Heat shock protein HSP 90-alpha & 1 & & 37.81 & 84.2 & 5.02 & No \\
\hline V5HRY6 & $\begin{array}{l}\text { Sodium/potassium-transporting ATPase } \\
\text { subunit alpha-B }\end{array}$ & 3 & & 144.31 & 91.7 & 5.16 & No \\
\hline A0A131XXE4 & F-box only protein 11 & 1 & 37.74 & & 99.1 & 7.06 & No \\
\hline A0A131XWG4 & Coatomer subunit beta & 2 & & 59.80 & 103.2 & 5.21 & No \\
\hline V5GY25 & Clathrin heavy chain $1^{*}$ & 3 & 35.11 & 119.33 & 190.7 & 5.81 & No \\
\hline V5I4B8 & Myosin heavy chain, muscle isoform X3 ${ }^{*}$ & 40 & 1378.54 & 1750.99 & 222.0 & 6.09 & No \\
\hline V5I3C9 & Myosin heavy chain, non-muscle isoform X1 * & 15 & 354.64 & 650.15 & 227.5 & 5.55 & No \\
\hline
\end{tabular}

* indicates a protein identified by LC-MS/MS in both ME and SGE following co-immunoprecipitation with antisera raised against ME and SGE, respectively. Entries with the same superscript letter in the protein description ${ }^{\mathrm{a}, \mathrm{b}}$ represent different fragments of the same protein.

\subsection{Expression of Recombinant Immunodominant Proteins and Validation by Western Blot}

Validation of the LC-MS/MS analysis was performed by the recombinant expression of two identified proteins that were differentially recognized by the immune sera: a putative Toll-like receptor (SG4, UNIPROT ID A0A0K8RQF1) from the SGE and an uncharacterized protein (MG9, UNIPROT ID A0A131YAQ2) from the ME. Western blot analysis confirmed the differential recognition of these two proteins (Figure 2). 
Table 4. List of proteins identified by LC-MS/MS from Ixodes ricinus midgut extracts (ME) following co-immunoprecipitation with antisera raised against ME. The Mascot score reflects the combined scores of all observed mass spectra that matched to amino acid sequences within the respective protein. MW: molecular weight.

\begin{tabular}{|c|c|c|c|c|c|c|c|}
\hline $\begin{array}{l}\text { Uniprot } \\
\text { Accession Code }\end{array}$ & Protein Name & $\begin{array}{l}\text { \# of Unique } \\
\text { Peptides }\end{array}$ & $\begin{array}{l}\text { Mascot } \\
\text { Score d0 }\end{array}$ & $\begin{array}{c}\text { Mascot } \\
\text { Score d68 }\end{array}$ & MW (kDa) & pI & $\begin{array}{l}\text { Signal } \\
\text { Peptide }\end{array}$ \\
\hline V5H4T2 & $\begin{array}{l}\text { Trifunctional purine biosynthetic protein } \\
\text { adenosine- } 3 \text { * }\end{array}$ & 1 & 52.26 & & 7.3 & 8.19 & No \\
\hline V5HY31 & Histone H4-like, putative & 1 & & 37.81 & 9.8 & 10.43 & No \\
\hline A0A0K8RK 48 & Uncharacterized protein & 1 & 43.68 & 44.01 & 13.2 & 7.83 & Yes \\
\hline A0A0K8RQA6 & Ubiquitin & 1 & 47.08 & & 14.5 & 9.82 & No \\
\hline V5H0K4 & Pantetheinase, putative ${ }^{a}$ & 1 & & 161.39 & 16.3 & 6.54 & Yes \\
\hline A0A131Y7G4 & Uncharacterized protein ${ }^{b}$ & 1 & 58.35 & 84.84 & 18.2 & 8.29 & Yes \\
\hline V5I2L3 & ADP / ATP translocase, putative (=MG4) & 1 & & 42.62 & 19.3 & 9.58 & No \\
\hline V5I135 & Alpha-crystallin A chain * & 1 & 110.22 & & 20.3 & 7.64 & No \\
\hline A0A090X8W5 & Uncharacterized protein ${ }^{b}$ & 1 & 73.12 & 61.59 & 21.7 & 8.94 & Yes \\
\hline A0A131YAP7 & Tropomyosin isoform X15/X16 & 1 & 61.58 & & 23.6 & 4.74 & No \\
\hline V5HHC0 & Uncharacterized protein & 1 & 58.35 & 95.16 & 23.8 & 9.85 & Yes \\
\hline A0A131XX88 & $60 S$ ribosomal protein L19 & 1 & 44.69 & & 24.2 & 11.43 & No \\
\hline A0A131XRL8 & Cathepsin L & 1 & & 72.31 & 27.7 & 5.48 & No \\
\hline A0A131XWI1 & $\begin{array}{l}\text { Salivary secreted cytotoxin, putative } \\
\text { (=MG1) }\end{array}$ & 1 & & 66.40 & 32.0 & 9.33 & No \\
\hline V5HBQ2 & Lysosomal Pro-X carboxypeptidase & 1 & & 40.01 & 33.9 & 5.08 & No \\
\hline V5HWP4 & Uncharacterized protein (=MG3) & 1 & & 48.01 & 35.0 & 7.01 & No \\
\hline A0A0K8RNA0 & Malate dehydrogenase & 2 & 73.48 & & 35.8 & 9.09 & No \\
\hline A0A0K8RG01 & $\begin{array}{l}\text { Glyceraldehyde-3-phosphate } \\
\text { dehydrogenase } 2 \text { isoform X1 * }\end{array}$ & 1 & 39.91 & & 36.0 & 7.84 & No \\
\hline E3SS18 & Translation elongation factor EF1-alpha * & 3 & 54.98 & 36.81 & 36.7 & 8.27 & No \\
\hline Q5D579 & Actin * & 7 & 248.34 & 38.91 & 41.5 & 5.85 & No \\
\hline A0A0K8RCB1 & Enolase & 1 & 38.63 & & 47.1 & 6.01 & No \\
\hline A0A131XPI3 & Aminopeptidase, putative W07G4.4 & 1 & & 34.48 & 47.6 & 8.32 & No \\
\hline A0A147BSS4 & Pantetheinase ${ }^{a}$ & 1 & & 206.82 & 52.5 & 7.01 & Yes \\
\hline A0A131XNF3 & $\begin{array}{c}\text { Processing peptidase beta subunit, } \\
\text { putative * }\end{array}$ & 1 & 50.89 & & 53.4 & 6.15 & No \\
\hline V5HEY6 & Alpha-L-fucosidase & 1 & & 55.17 & 53.5 & 6.92 & Yes \\
\hline V5HB74 & Retinal dehydrogenase 1 & 4 & 181.55 & 90.92 & 54.6 & 6.89 & No \\
\hline V5IJN2 & $\begin{array}{l}\text { Calcium-activated chloride channel } \\
\text { regulator (=MG7) }\end{array}$ & 1 & & 39.96 & 55.1 & 4.96 & No \\
\hline A0A131Y0J3 & $\begin{array}{l}\text { Alpha-aminoadipic semialdehyde } \\
\text { dehydrogenase }\end{array}$ & 1 & 39.78 & & 58.7 & 6.79 & No \\
\hline A0A131XPM3 & Heat shock protein $60 *$ & 1 & & 89.26 & 59.3 & 5.62 & No \\
\hline A0A0K8RCE8 & Heat shock $70 \mathrm{kDa}$ protein cognate $4^{*}$ & 3 & 171.54 & & 59.8 & 7.43 & No \\
\hline A0A131XQI6 & Moesin/ezrin/radixin homolog $1 *$ & 1 & 97.17 & & 62.5 & 5.52 & No \\
\hline V5HN24 & Beta-hexosaminidase subunit beta & 1 & & 38.14 & 63.4 & 5.40 & No \\
\hline A0A0K8RIU3 & Heat shock protein, putative ${ }^{*}$ & 3 & 179.61 & & 72.6 & 5.41 & Yes \\
\hline A0A0K8R8I3 & $\begin{array}{l}\text { Uncharacterized protein (cubilin-like?) } \\
\text { (=MG5) }\end{array}$ & 2 & & 80.81 & 75.8 & 6.67 & Yes \\
\hline V5IFB6 & Integrin beta-PS (=MG2) & 3 & & 193.69 & 83.8 & 5.17 & No \\
\hline V5GPX7 & Alpha-actinin isoform $\mathrm{X} 2$ & 1 & & 38.52 & 89.4 & 6.13 & No \\
\hline A0A131YAQ2 & Uncharacterized protein (=MG9) & 1 & & 71.18 & 94.3 & 6.62 & Yes \\
\hline A0A147BXB7 & Cell adhesion molecule, putative (=MG6) & 3 & & 70.59 & 104.8 & 6.34 & Yes \\
\hline A0A147BMG4 & Uncharacterized protein (=MG8) & 1 & & 34.22 & 109.1 & 5.95 & Yes \\
\hline A0A0K8RQE7 & Lysosomal alpha-mannosidase-like & 1 & & 62.70 & 109.3 & 7.56 & No \\
\hline V5H492 & Integrin alpha-PS1 (=MG10) & 1 & & 43.73 & 110.3 & 6.14 & No \\
\hline V5H7Z4 & Alpha-2-macroglobulin-like protein & 2 & & 114.53 & 152.0 & 5.59 & Yes \\
\hline V5GY25 & Clathrin heavy chain $1 *$ & 1 & 47.55 & & 190.7 & 5.81 & No \\
\hline V5I4B8 & Myosin heavy chain, muscle isoform X3 * & 6 & 178.22 & 52.04 & 222.0 & 6.09 & No \\
\hline V5I3C9 & $\begin{array}{l}\text { Myosin heavy chain, non-muscle isoform } \\
\qquad \mathrm{X} 1 \text { * }\end{array}$ & 6 & 68.25 & 71.36 & 227.5 & 5.55 & No \\
\hline A0A131XS30 & $\begin{array}{c}\text { MAM and LDL-receptor class A } \\
\text { domain-containing protein } 1 \text { (=MG11) }\end{array}$ & 1 & & 40.27 & 420.4 & 5.49 & No \\
\hline
\end{tabular}

* indicates a protein identified by LC-MS/MS in both ME and SGE following co-immunoprecipitation with antisera raised against ME and SGE, respectively. Entries with the same superscript letter in the protein descriptions ${ }^{a, b}$ represent different fragments of the same protein. 


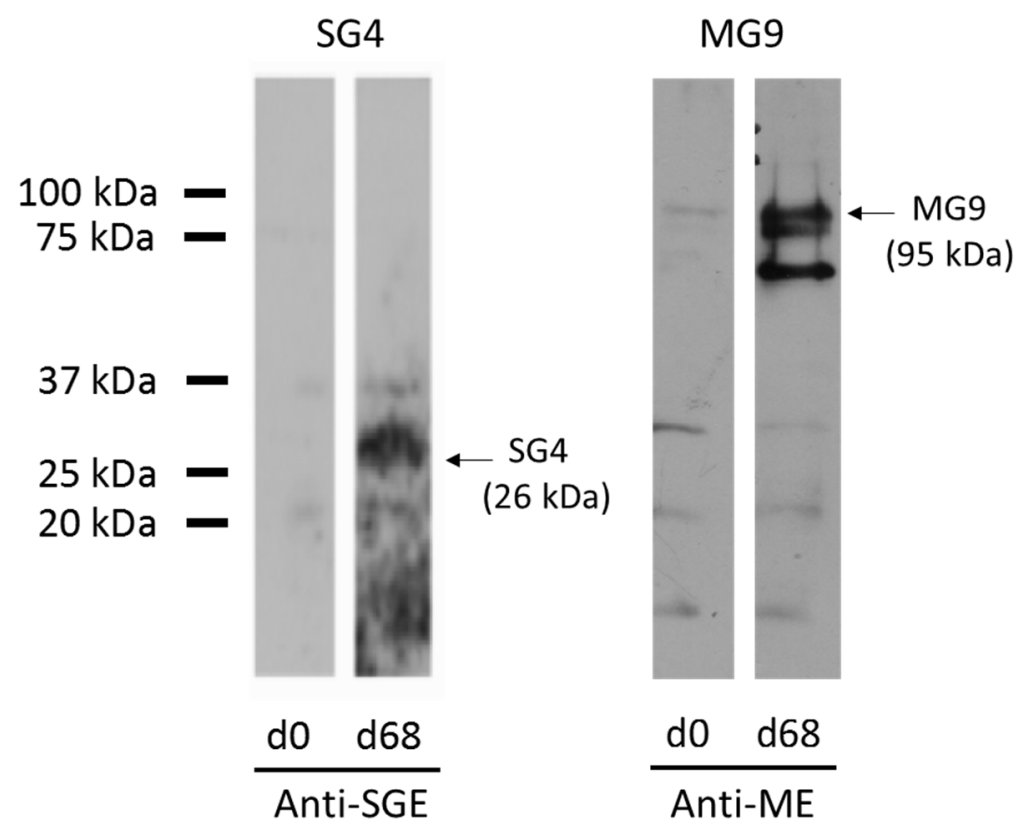

Figure 2. SG4 and MG9 Western blot as validation for the immunoprecipitation employed to identify new vaccine antigens ( $\mathrm{d} 0$ : control sera; $\mathrm{d} 68$ : immune sera).

\subsection{Expression Profile of Selected Genes in Different Tissues of Ixodes ricinus Females}

Eleven ME proteins and four SGE proteins were subsequently selected for further analysis based on their differential recognition by $\mathrm{d} 68$ sera, having putative extracellular exposure or being predicted to be secreted. The expression profile of these proteins was determined by quantitative RT-PCR. The results corroborated findings of the proteomic analysis since proteins identified by LC-MS/MS from SGE and ME immunoprecipitates were expressed in the salivary glands and midguts, respectively. Two salivary gland proteins (SG1 and SG3) that were predicted to be different fragments of the same metalloproteinase had similar expression profiles. A few proteins were expressed in salivary glands or midguts exclusively, such as the metalloproteinase mentioned above and two uncharacterized midgut proteins with unknown homology (MG8 and MG9). However, most of the proteins were expressed in multiple tick tissues (Figure 3).

\subsection{Effect of Gene Silencing of Selected Candidates on I. ricinus Adult Feeding}

Female ticks were injected with dsRNA complementary to GFP (control), SG2, MG1, MG2, MG4, MG6, MG7, MG8, MG9, MG10, or MG11, and were subsequently allowed to feed on rabbits. The proportion of ticks that were engorged was significantly lower for the MG2 $(p=0.0003)$, MG6 $(p<0.0001)$, MG8 $(p=0.0026)$, MG10 $(p<0.0001)$, and SG2 ( $p=0.0003)$ groups compared to the GFP control groups. The engorgement weights of both GFP-injected control groups were not significantly different, and the engorgement weights obtained in the experimental groups were compared to the weights of the combined control groups. Significantly lower engorgement weights were found for MG4 $(p=0.0025)$, MG6 $(p=0.0139)$, MG9 $(p=0.0213)$, and SG2 $(p=0.0356)$ (Figure 4). Quantitative RT-PCR showed that the expression of the target genes was silenced in each respective group, with the exception of MG11, where a non-significant increase in MG11 gene expression levels was found in the ticks injected with MG11 dsRNA (Figure 5). Significant gene silencing was found for MG1, MG2, MG7, MG9, MG10, and SG2 ( $t$-test, $p<0.05$ ). The lower expression levels detected for MG4 and MG6 were not significant. 

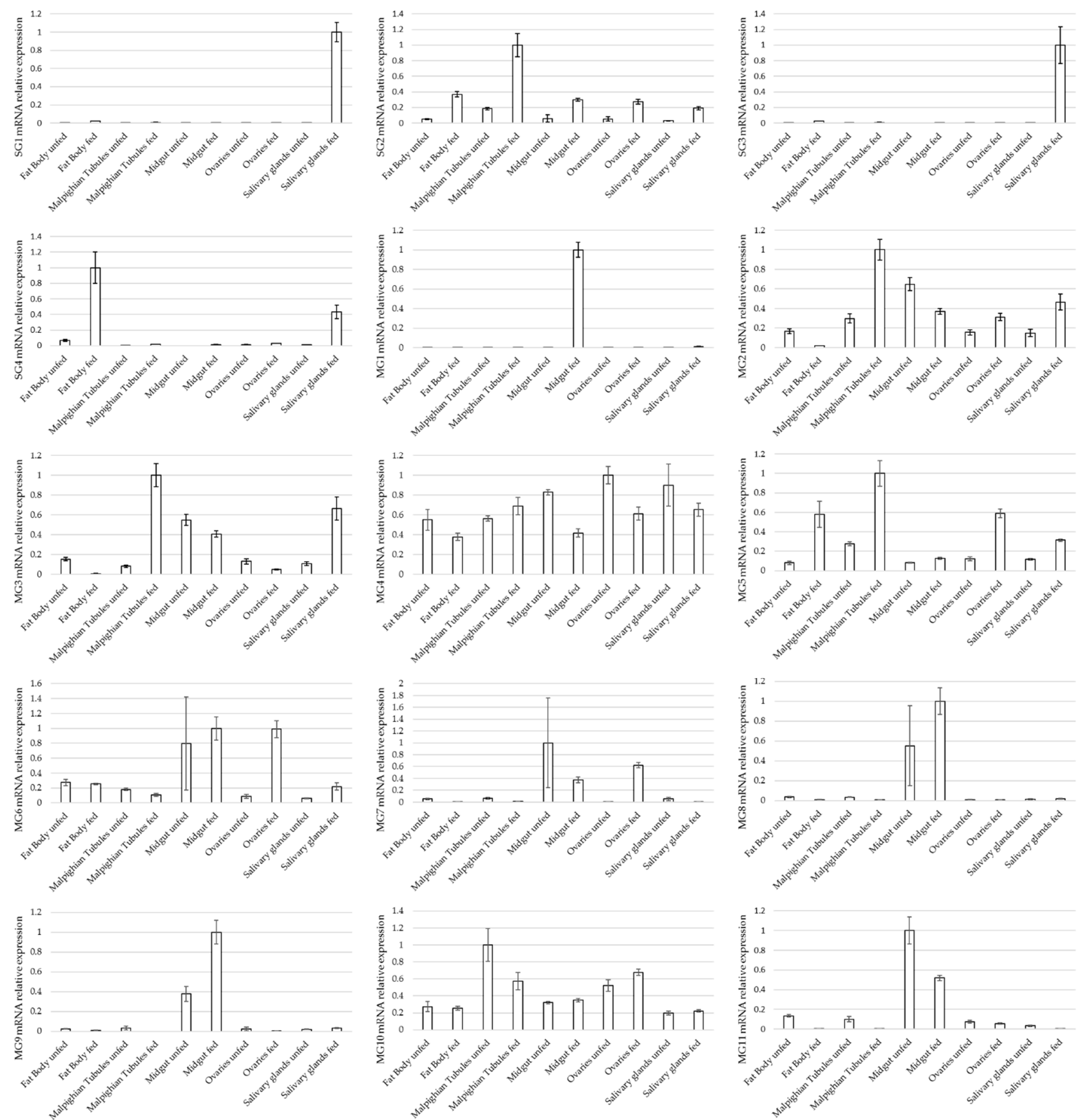

Figure 3. Relative gene expression of selected candidates identified by LC-MS/MS analysis of unfed and partially fed Ixodes ricinus females. Bars represent the standard deviation of the normalized gene expression. 


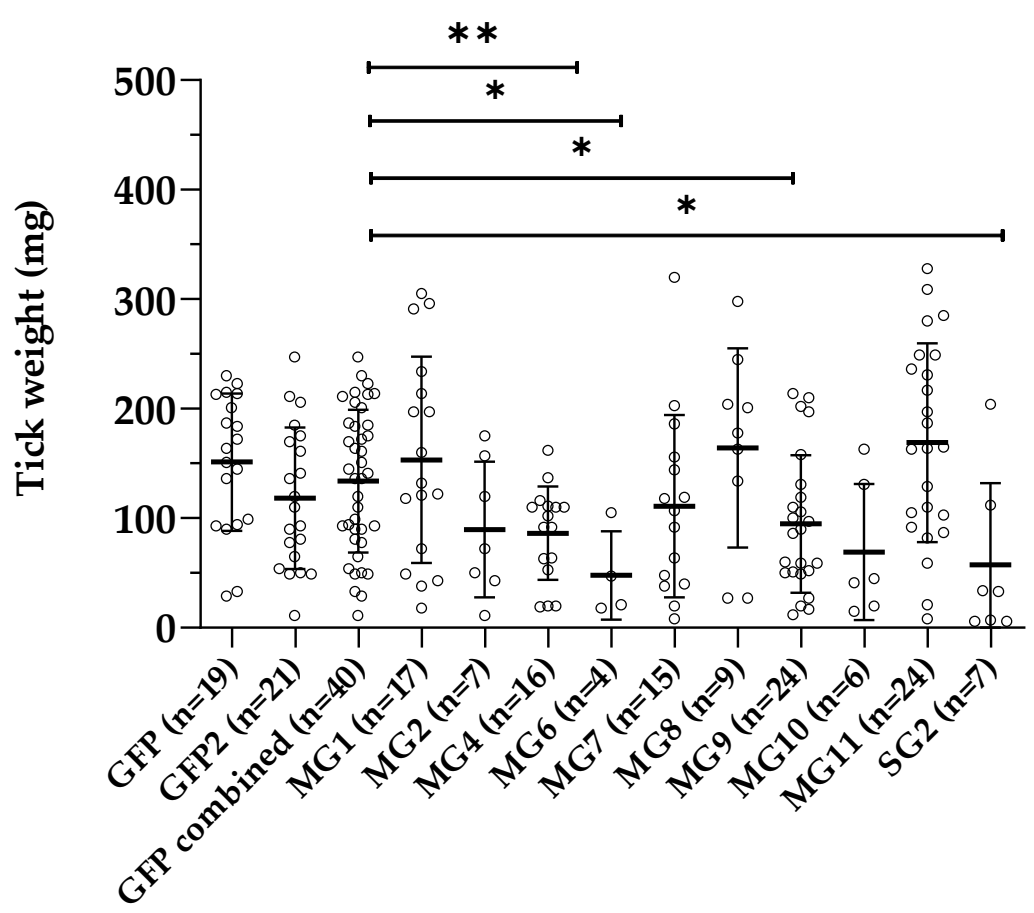

Figure 4. Weight of replete Ixodes ricinus females injected with dsRNA coding for GFP (control groups) and 10 gene targets identified by LC-MS/MS. Errors bars represent the standard deviation (SD). The asterixis indicate a significant difference in weight; ${ }^{*}(p<0.05),{ }^{* *}(p<0.005)$.
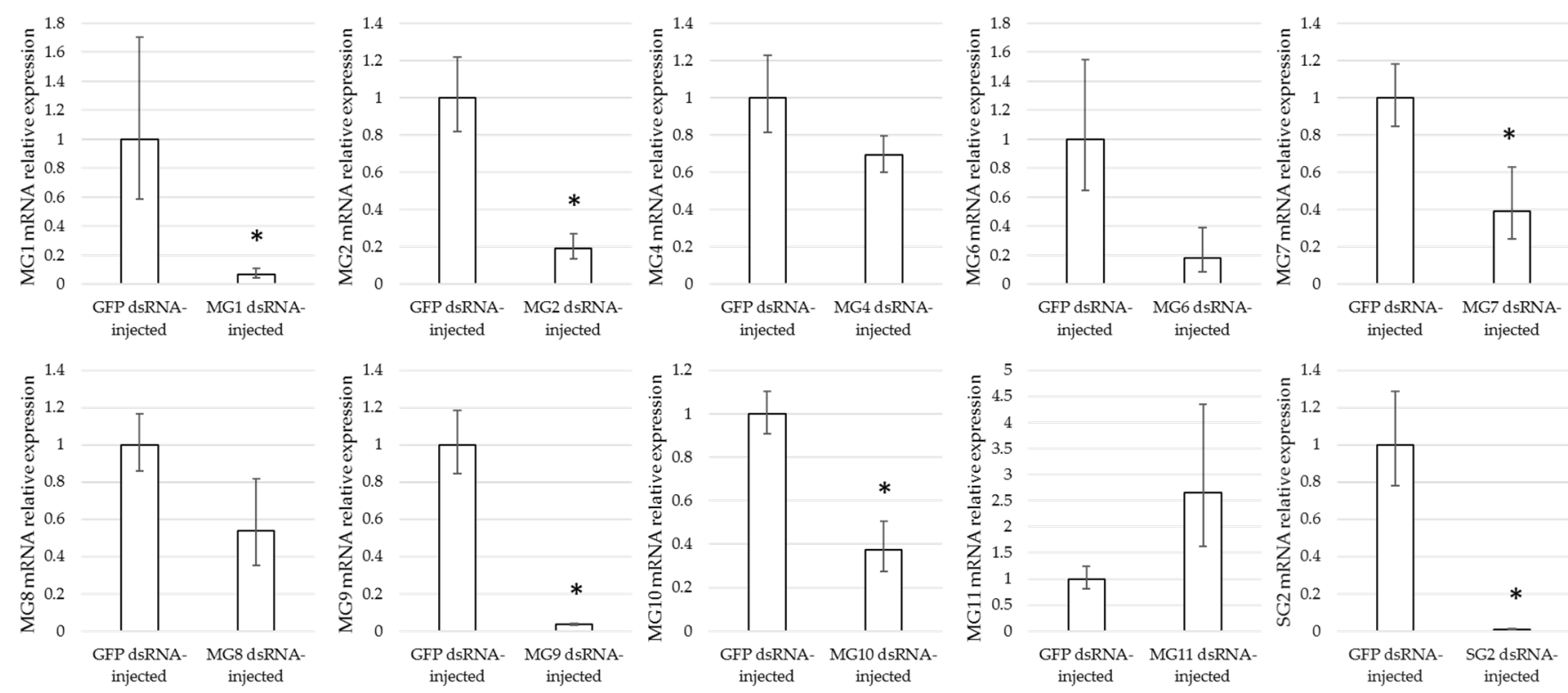

Figure 5. mRNA expression levels of target genes, relative to the expression in GFP-injected ticks. Compared to the control ticks, only the expression of target genes MG1, MG2, MG7, MG9, MG10, and SG2 was significantly knocked down in the respective experimental groups. ${ }^{*}$ indicates a significant difference between the control and experimental group $(p<0.05)$.

\section{Discussion}

The main bottleneck in the development of successful anti-tick vaccines is the identification of tick-protective antigens that are effective in limiting tick infestations when applied as recombinant antigens. Several approaches have been followed to identify tickprotective antigens, including studies of the immune response in tick-immune hosts, the evaluation of the increasingly simpler native protein extracts in vaccination, and challenge 
trials, as well as the identification of antigens that are crucial for the survival or function of ticks, for instance using functional genomic tools such as RNAi [7]. In this study, we used a combination of these approaches, starting with sera of calves immunized with tick extracts that showed a strong immune response upon I. ricinus tick challenge, which significantly hampered the feeding of both nymphs and adults [10]. The sera were used for the co-immunoprecipitation of tissue extracts, and differentially recognized proteins were subsequently identified by label-free LC-MS/MS, a step greatly facilitated by the increasing amounts of proteomic and genomic data that have become available for ticks over the last years [16]. Several differentially recognized antigens were subsequently characterized in more detail by determining their tissue expression profiles and loss-of-function phenotype by RNAi.

A considerable number of proteins identified by co-immunoprecipitation together with LC-MS/MS have previously also drawn attention as possible anti-tick vaccine candidates by other approaches. These include homologs of glutathione-S-transferase (SG2) [17-19], tropomyosin [20,21], ubiquitin and elongation factor EF1-alpha [22,23], myosin light chain [24], heat shock protein 70 [25], cathepsin L [26], enolase [27], antigen B from $R$. microplus (AAN15115) with 67.4\% (663/984 amino acid (AA)) identity to MG8 [28], a glyceraldehyde-3-phosphate dehydrogenase from Haemaphysalis flava (AVK70348) with 88.2\% (293/332 AA) identity to A0A0K8RG01 [29], and SG1/SG3 (A0A0K8RPW5/V5HWD5), a metalloproteinase with 60.2\% (136/226 AA) identity to metis 5 from I. ricinus (CAO00629) [30,31].

Glutathione-S-transferases (GSTs) play a role in the excretion of toxic metabolites, and the partially characterized GST SG2 (A0A0K8RKT7) shares 88.3\% (197/223) AA identity with DmGSTM1, a mu-class GST from Dermacentor marginatus ticks that was recently evaluated as an anti-tick vaccine $[17,18]$. SG2 also had a similar expression pattern in the tissues of adult females to DmGSTM1 [17]. Gene silencing of GSTs was previously shown to increase the susceptibility of Rhipicephalus sanguineus and Haemaphysalis longicornis ticks to the ectoparasiticides permethrin and flumethrin, respectively [32,33]. In our study, RNAi-mediated silencing of the expression of SG2 resulted in a smaller proportion of ticks that were engorged, with engorged ticks having significantly lower engorgement weights compared to the control group. Gene silencing of gst also significantly reduced the engorgement weights of $R$. microplus females [22], but not of $R$. sanguineus females [32]. These differences may have been caused by differences in the gst isoform targeted, experimental procedures, and/or RNAi efficiency.

The second protein that showed a clear loss-of-function phenotype in the RNAi study was MG6 (A0A147BXB7). This $105 \mathrm{kDa}$ protein is predicted to contain a signal peptide, eight fibronectin type III domains, and a single transmembrane protein. The fibronectin type III domain is one of three types of internal repeats found in fibronectin, a glycoprotein that connects cells to the extracellular matrix, plays a role in cell signaling, and may also act as a target for bacterial adhesion. Fibronectin type III domains also frequently occur as tandem repeats in cell surface proteins and in the extracellular regions of some cell surface receptors [34,35]. In ticks, Ixofin3D, an I. scapularis midgut protein containing a signal peptide, four putative fibronectin III domains and a transmembrane protein were shown to play a role in the aggregation of Borrelia burgdorferi on the gut epithelium [36]. Silencing of other fibronectin type III domain-containing proteins expressed in the gut of Anopheles arabiensis mosquitoes disrupted gut homeostasis following feeding and reduced mosquito longevity [37]. Taken together, it is tempting to speculate that MG6 could also act as a modulator for the bacterial population structure in the tick gut, whereby silencing of MG6 could lead to reduced feeding success and increased tick mortality due to disruption of the gut homeostasis. Additional studies will be required to examine the physiological function of MG6 and its potential as a tick-protective antigen within an anti-tick vaccine in more detail.

Although the injection of dsRNA in the haemocoel of ticks usually results in a systemic RNAi response, the RNAi efficiency may vary between target genes and experiments. In our study, silencing levels ranged from $~ 96 \%$ in the expression of MG9 (A0A131YAQ2) to 
a complete absence of gene silencing in ticks injected with MG11 (A0A131XS30)-dsRNA, suggesting that MG11 is a refractory target gene for RNAi (Figure 5). In insects, other factors than the target gene, such as the targeted species, strain, tissue and life stage have also been reported to play a role in RNAi efficiency [38]. These and other factors, such as the optimal dsRNA amount for RNAi, have not yet been systematically investigated in ticks, although differences in RNAi efficiency between tick cell lines have been reported [39].

Significantly lower engorgement weights were found for the MG4-silenced females, despite a limited reduction ( $31 \%$ ) in MG4 transcript levels. MG4 is a putative ADP/ATP translocase also known as the adenine nucleotide translocator (ANT) protein, which exchanges ADP/ATP through the mitochondrial inner membrane and is essential for the cellular energy metabolism. In most eukaryotes, multiple ANT proteins are present, with some paralogs being exclusively expressed in testicular germ cells, where they are thought to be essential for spermatogenesis by supplying meiotic cells with ATP [40]. The ubiquitous expression of MG4 and its RNAi phenotype suggest that this protein has a critical role in organismal homeostasis. The high level of amino acid sequence homology of vertebrate and arthropod ANTs [40] may however limit the usability of this protein as an anti-tick vaccine antigen.

Significantly lower engorgement weights were also found for MG9-silenced females. Since the coding sequence for MG9 (A0A131YAQ2) does not contain a stop codon, it is likely to be a truncated version of I. ricinus protein V5ICT5, with which it shares $99 \%$ AA sequence identity. V5ICT5 is an uncharacterized protein of 1003 amino acids with a predicted mass of $113 \mathrm{kDa}$. It has a signal peptide, three apple domains, and a transmembrane domain. MG8 (A0A147BMG4), the silencing of which led to a significant reduction in females that fed successively but had no effect on the engorgement weight, has a similar structure with a signal peptide, four apple domains as well as a transmembrane protein. Apple domains are characterized by six cystine residues at highly conserved positions that through the formation of disulfide bonds form a structure which resembles an apple when drawn [41]. These domains are also present on plasma proteins such as factor XI and prekallikrein, where they are essential for binding of substrates [42,43]. The exclusive expression of MG8 and MG9 in the tick midgut, their upregulation upon feeding, and RNAi phenotypes warrant further studies into the function of these proteins.

The proportion of ticks that were successfully engorged was reduced in the MG2 (V5IFB6) and MG10 (V5H492)-silenced females, homologs of the integrin beta and integrin alpha subunits, respectively. Integrins function as cell surface receptors, providing a transmembrane link between the extracellular matrix and the cytoskeleton. Silencing of the expression of integrin beta subunits also had detrimental effects on the development of other arthropods such as the Oriental tobacco budworm, Helicoverpa assulta, and the beet armyworm, Spodoptera exigua $[44,45]$.

\section{Conclusions}

Co-immunoprecipitation of tick tissue extracts with bovine immune serum raised against these extracts followed by LC-MS/MS analysis led to the identification of immunodominant proteins. This included several proteins that had previously raised interest as potential anti-tick vaccine antigens. Gene silencing of seven out of 11 selected immunodominant proteins targets resulted in a significantly decreased engorgement weight (MG4, MG6, MG9, and SG2) and /or a significant reduction in the number of ticks that successfully engorged (MG2, MG6, MG8, MG10, and SG2) compared to GFP-injected control groups. Although definite proof in the form of vaccination trials against these proteins remains outstanding, we tentatively conclude that the followed approach may be useful in anti-tick vaccine antigen discovery pipelines.

Author Contributions: Conceptualization, S.K., J.A., J.W.H., A.M.N.; methodology, S.K., J.A., A.M.N.; software, S.K., S.R.-O.; validation, S.K., S.R.-O., S.P.-S.; formal analysis, S.K., S.R.-O., A.M.N.; investigation, S.K., S.R.-O., J.T.-C., D.B., M.A., I.I., F.E., S.P.-S., J.A., A.M.N.; resources, J.A., A.M.N.; data curation, S.K., S.R.-O., S.P.-S.; writing-original draft preparation, S.K., S.R.-O., A.M.N.; writing- 
review and editing, J.T.-C., J.A., F.E., J.W.H.; visualization, A.M.N.; supervision, A.M.N.; project administration, A.M.N.; funding acquisition, J.A., J.W.H., A.M.N. All authors have read and agreed to the published version of the manuscript.

Funding: This research was funded by the European Community's Seventh Framework Program under grant agreement 602272. A.M.N. and S.P.-S. received financial support from the Federal Ministry of Education and Research (BMBF) under project number 01KI1720 as part of the 'Research Network Zoonotic Infectious Diseases'. CIC bioGUNE is accredited as a Severo Ochoa Center of Excellence by the Spanish Ministry of Science and Innovation (MCI, SEV-2016-0644). D.B. is supported by an MCI predoctoral fellowship. J.T.-C. is a recipient of a postdoctoral award from the Basque Government. J.A. and D.B. acknowledge the support of the Jesús de Gangoiti Barrera Foundation.

Institutional Review Board Statement: Ethical approval for the maintenance of the used I. ricinus laboratory colony on experimental animals was provided by the "Landesamt für Gesundheit und Soziales" (LAGeSo) of Berlin under registration number H0387/17. Ethical approval for the feeding of dsRNA-injected ticks on rabbits was granted by the LAGeSo under registration number G 0193/15.

Informed Consent Statement: Not applicable.

Data Availability Statement: All the data are included within the article.

Conflicts of Interest: The authors declare no conflict of interest.

\section{References}

1. Heyman, P.; Cochez, C.; Hofhuis, A.; van der Giessen, J.; Sprong, H.; Porter, S.R.; Losson, B.; Saegerman, C.; Donoso-Mantke, O.; Niedrig, M.; et al. A clear and present danger: Tick-borne diseases in Europe. Expert Rev. Anti-Infect. Ther. 2010, 8, 33-50. [CrossRef]

2. Apostolovic, D.; Mihailovic, J.; Commins, S.P.; Wijnveld, M.; Kazimirova, M.; Starkhammar, M.; Stockinger, H.; Platts-Mills, T.A.E.; Cirkovic Velickovic, T.; Hamsten, C.; et al. Allergenomics of the tick Ixodes ricinus reveals important alpha-Gal-carrying IgE-binding proteins in red meat allergy. Allergy 2020, 75, 217-220. [CrossRef]

3. Apostolovic, D.; Tran, T.A.; Starkhammar, M.; Sanchez-Vidaurre, S.; Hamsten, C.; Van Hage, M. The red meat allergy syndrome in Sweden. Allergo J. Int. 2016, 25, 49-54. [CrossRef] [PubMed]

4. Sprong, H.; Azagi, T.; Hoornstra, D.; Nijhof, A.M.; Knorr, S.; Baarsma, M.E.; Hovius, J.W. Control of Lyme borreliosis and other Ixodes ricinus-borne diseases. Parasites Vectors 2018, 11, 145. [CrossRef]

5. Embers, M.E.; Narasimhan, S. Vaccination against Lyme disease: Past, present, and future. Front. Cell. Infect. Microbiol. 2013, 3, 6. [CrossRef] [PubMed]

6. Rego, R.O.M.; Trentelman, J.J.A.; Anguita, J.; Nijhof, A.M.; Sprong, H.; Klempa, B.; Hajdusek, O.; Tomas-Cortazar, J.; Azagi, T.; Strnad, M.; et al. Counterattacking the tick bite: Towards a rational design of anti-tick vaccines targeting pathogen transmission. Parasites Vectors 2019, 12, 229. [CrossRef] [PubMed]

7. Koci, J.; Bista, S.; Chirania, P.; Yang, X.; Kitsou, C.; Rana, V.S.; Yas, O.B.; Sonenshine, D.E.; Pal, U. Antibodies against EGF-like domains in Ixodes scapularis BM86 orthologs impact tick feeding and survival of Borrelia burgdorferi. Sci. Rep. 2021, 11, 6095. [CrossRef]

8. de la Fuente, J.; Almazan, C.; Canales, M.; de la Lastra, J.M.P.; Kocan, K.M.; Willadsen, P. A ten-year review of commercial vaccine performance for control of tick infestations on cattle. Anim. Health Res. Rev. 2007, 8, 23-28. [CrossRef]

9. Willadsen, P. Anti-tick vaccines. Parasitology 2004, 129, S367-S387. [CrossRef] [PubMed]

10. Willadsen, P.; Riding, G.A.; McKenna, R.V.; Kemp, D.H.; Tellam, R.L.; Nielsen, J.N.; Lahnstein, J.; Cobon, G.S.; Gough, J.M. Immunologic control of a parasitic arthropod. Identification of a protective antigen from Boophilus microplus. J. Immunol. 1989, 143, 1346-1351. [PubMed]

11. Kemp, D.H.; Agbede, R.I.; Johnston, L.A.; Gough, J.M. Immunization of cattle against Boophilus microplus using extracts derived from adult female ticks: Feeding and survival of the parasite on vaccinated cattle. Int. J. Parasitol. 1986, 16, 115-120. [CrossRef]

12. Trentelman, J.J.A.; Teunissen, H.; Kleuskens, J.; van de Crommert, J.; de la Fuente, J.; Hovius, J.W.R.; Schetters, T.P.M. A combination of antibodies against Bm86 and Subolesin inhibits engorgement of Rhipicephalus australis (formerly Rhipicephalus microplus) larvae in vitro. Parasites Vectors 2019, 12, 362. [CrossRef] [PubMed]

13. Knorr, S.; Anguita, J.; Cortazar, J.T.; Hajdusek, O.; Kopacek, P.; Trentelman, J.J.; Kershaw, O.; Hovius, J.W.; Nijhof, A.M. Preliminary evaluation of tick protein extracts and recombinant Ferritin 2 as anti-tick vaccines targeting Ixodes ricinus in cattle. Front. Physiol. 2018, 9, 1696. [CrossRef]

14. Nijhof, A.M.; Balk, J.A.; Postigo, M.; Jongejan, F. Selection of reference genes for quantitative RT-PCR studies in Rhipicephalus (Boophilus) microplus and Rhipicephalus appendiculatus ticks and determination of the expression profile of Bm86. BMC Mol. Biol. 2009, 10, 112. [CrossRef] 
15. Trentelman, J.J.A.; Sima, R.; Krezdorn, N.; Tomas-Cortazar, J.; Barriales, D.; Takumi, K.; Butler, J.M.; Sprong, H.; Klouwens, M.J.; Urbanova, V.; et al. A combined transcriptomic approach to identify candidates for an anti-tick vaccine blocking B. afzelii transmission. Sci. Rep. 2020, 10, 20061. [CrossRef] [PubMed]

16. Mans, B.J. Quantitative visions of reality at the tick-host interface: Biochemistry, genomics, proteomics, and transcriptomics as measures of complete inventories of the tick sialoverse. Front. Cell. Infect. Microbiol. 2020, 10, 574405. [CrossRef]

17. Huercha; Ma, Y.; Hao, Y.; Li, M.; Hu, Z.; Song, R.; Wei, L.; Fan, S.; Chen, S.; Fan, X.; et al. Sequence identification and expression profile of seven Dermacentor marginatus glutathione S-transferase genes. Exp. Appl. Acarol. 2020, 82, 295-308. [CrossRef]

18. Huercha; Song, R.; Li, M.; Fan, X.; Hu, Z.; Wu, L.; Li, Y.; Zhang, W.; Zhang, Y.; Ma, Y.; et al. Caracterization of glutathione S-transferase of Dermacantor marginatus and effect of the recombinant antigen as a potential anti-tick vaccine. Vet. Parasitol. 2020, 279, 109043. [CrossRef]

19. Ndawula, C., Jr.; Sabadin, G.A.; Parizi, L.F.; da Silva Vaz, I., Jr. Constituting a glutathione S-transferase-cocktail vaccine against tick infestation. Vaccine 2019, 37, 1918-1927. [CrossRef]

20. Manjunathachar, H.V.; Kumar, B.; Saravanan, B.C.; Choudhary, S.; Mohanty, A.K.; Nagar, G.; Chigure, G.; Ravi Kumar, G.; de la Fuente, J.; Ghosh, S. Identification and characterization of vaccine candidates against Hyalomma anatolicum-Vector of Crimean-Congo haemorrhagic fever virus. Transbound. Emerg. Dis. 2019, 66, 422-434. [CrossRef]

21. Tian, M.; Tian, Z.; Luo, J.; Xie, J.; Yin, H.; Zeng, Q.; Shen, H.; Chai, H.; Yuan, X.; Wang, F.; et al. Identification of the tropomyosin (HL-Tm) in Haemaphysalis longicornis. Vet. Parasitol. 2015, 207, 318-323. [CrossRef]

22. Almazan, C.; Lagunes, R.; Villar, M.; Canales, M.; Rosario-Cruz, R.; Jongejan, F.; de la Fuente, J. Identification and characterization of Rhipicephalus (Boophilus) microplus candidate protective antigens for the control of cattle tick infestations. Parasitol. Res. 2010, 106, 471-479. [CrossRef]

23. Almazan, C.; Moreno-Cantu, O.; Moreno-Cid, J.A.; Galindo, R.C.; Canales, M.; Villar, M.; de la Fuente, J. Control of tick infestations in cattle vaccinated with bacterial membranes containing surface-exposed tick protective antigens. Vaccine 2012, 30, 265-272. [CrossRef]

24. Gao, J.; Luo, J.; Fan, R.; Guan, G.; Ren, Q.; Ma, M.; Sugimoto, C.; Bai, Q.; Yin, H. Molecular characterization of a myosin alkali light chain-like protein, a "concealed" antigen from the hard tick Haemaphysalis qinghaiensis. Vet. Parasitol. 2007, 147, 140-149. [CrossRef]

25. Tian, Z.; Liu, G.; Zhang, L.; Yin, H.; Wang, H.; Xie, J.; Zhang, P.; Luo, J. Identification of the heat shock protein 70 (HLHsp70) in Haemaphysalis longicornis. Vet. Parasitol. 2011, 181, 282-290. [CrossRef]

26. Kumar, B.; Manjunathachar, H.V.; Nagar, G.; Ravikumar, G.; de la Fuente, J.; Saravanan, B.C.; Ghosh, S. Functional characterization of candidate antigens of Hyalomma anatolicum and evaluation of its cross-protective efficacy against Rhipicephalus microplus. Vaccine 2017, 35, 5682-5692. [CrossRef]

27. Diaz-Martin, V.; Manzano-Roman, R.; Oleaga, A.; Encinas-Grandes, A.; Perez-Sanchez, R. Cloning and characterization of a plasminogen-binding enolase from the saliva of the argasid tick Ornithodoros moubata. Vet. Parasitol. 2013, 191, 301-314. [CrossRef]

28. Willadsen, P. The Development of a New or Improved Vaccine against Boophilus microplus: Opportunities for RED Investment; Meat \& Livestock Australia Limited: Sydney, Australia, 2008.

29. Xu, L.; Liu, L.; Cheng, T.Y. Cloning and expression profile of glyceraldehyde-3-phosphate dehydrogenase in Haemaphysalis flava (Acari: Ixodidae). J. Med. Entomol. 2019, 56, 569-575. [CrossRef] [PubMed]

30. Decrem, Y.; Beaufays, J.; Blasioli, V.; Lahaye, K.; Brossard, M.; Vanhamme, L.; Godfroid, E. A family of putative metalloproteases in the salivary glands of the tick Ixodes ricinus. FEBS J. 2008, 275, 1485-1499. [CrossRef] [PubMed]

31. Decrem, Y.; Mariller, M.; Lahaye, K.; Blasioli, V.; Beaufays, J.; Boudjeltia, K.Z.; Vanhaeverbeek, M.; Cerutti, M.; Brossard, M.; Vanhamme, L.; et al. The impact of gene knock-down and vaccination against salivary metalloproteases on blood feeding and egg laying by Ixodes ricinus. Int. J. Parasitol. 2008, 38, 549-560. [CrossRef] [PubMed]

32. Duscher, G.G.; Galindo, R.C.; Tichy, A.; Hummel, K.; Kocan, K.M.; de la Fuente, J. Glutathione S-transferase affects permethrin detoxification in the brown dog tick, Rhipicephalus sanguineus. Ticks Tick Borne Dis. 2014, 5, 225-233. [CrossRef]

33. Hernandez, E.P.; Kusakisako, K.; Talactac, M.R.; Galay, R.L.; Hatta, T.; Fujisaki, K.; Tsuji, N.; Tanaka, T. Glutathione S-transferases play a role in the detoxification of flumethrin and chlorpyrifos in Haemaphysalis longicornis. Parasites Vectors 2018, 11, 460. [CrossRef]

34. Henderson, B.; Nair, S.; Pallas, J.; Williams, M.A. Fibronectin: A multidomain host adhesin targeted by bacterial fibronectinbinding proteins. FEMS Microbiol. Rev. 2011, 35, 147-200. [CrossRef] [PubMed]

35. Vaca, D.J.; Thibau, A.; Schutz, M.; Kraiczy, P.; Happonen, L.; Malmstrom, J.; Kempf, V.A.J. Interaction with the host: The role of fibronectin and extracellular matrix proteins in the adhesion of Gram-negative bacteria. Med. Microbiol. Immunol. 2020, 209, 277-299. [CrossRef] [PubMed]

36. Narasimhan, S.; Coumou, J.; Schuijt, T.J.; Boder, E.; Hovius, J.W.; Fikrig, E. A tick gut protein with fibronectin III domains aids Borrelia burgdorferi congregation to the gut during transmission. PLoS Pathog. 2014, 10, e1004278. [CrossRef] [PubMed]

37. Debalke, S.; Habtewold, T.; Duchateau, L.; Christophides, G.K. The effect of silencing immunity related genes on longevity in a naturally occurring Anopheles arabiensis mosquito population from southwest Ethiopia. Parasites Vectors 2019, 12, 174. [CrossRef]

38. Cooper, A.M.; Silver, K.; Zhang, J.; Park, Y.; Zhu, K.Y. Molecular mechanisms influencing efficiency of RNA interference in insects Pest Manag. Sci. 2019, 75, 18-28. [CrossRef] 
39. Barry, G.; Alberdi, P.; Schnettler, E.; Weisheit, S.; Kohl, A.; Fazakerley, J.K.; Bell-Sakyi, L. Gene silencing in tick cell lines using small interfering or long double-stranded RNA. Exp. Appl. Acarol. 2013, 59, 319-338. [CrossRef]

40. Sugahara, R.; Jouraku, A.; Nakakura, T.; Kusakabe, T.; Yamamoto, T.; Shinohara, Y.; Miyoshi, H.; Shiotsuki, T. Two adenine nucleotide translocase paralogues involved in cell proliferation and spermatogenesis in the silkworm Bombyx mori. PLoS ONE 2015, 10, e0119429. [CrossRef]

41. Sigrist, C.J.; de Castro, E.; Cerutti, L.; Cuche, B.A.; Hulo, N.; Bridge, A.; Bougueleret, L.; Xenarios, I. New and continuing developments at PROSITE. Nucleic Acids Res. 2013, 41, D344-D347. [CrossRef]

42. Renne, T.; Dedio, J.; Meijers, J.C.; Chung, D.; Muller-Esterl, W. Mapping of the discontinuous H-kininogen binding site of plasma prekallikrein. Evidence for a critical role of apple domain-2. J. Biol. Chem. 1999, 274, 25777-25784. [CrossRef] [PubMed]

43. Ho, D.H.; Badellino, K.; Baglia, F.A.; Walsh, P.N. A binding site for heparin in the apple 3 domain of factor XI. J. Biol. Chem. 1998, 273, 16382-16390. [CrossRef] [PubMed]

44. Surakasi, V.P.; Mohamed, A.A.; Kim, Y. RNA interference of beta1 integrin subunit impairs development and immune responses of the beet armyworm, Spodoptera exigua. J. Insect. Physiol. 2011, 57, 1537-1544. [CrossRef] [PubMed]

45. Park, Y.; Ahn, S.J.; Vogel, H.; Kim, Y. Integrin beta subunit and its RNA interference in immune and developmental processes of the Oriental tobacco budworm, Helicoverpa assulta. Dev. Comp. Immunol. 2014, 47, 59-67. [CrossRef] 